Dicle University Journal of Engineering (DUJE)

web: http://dergipark.gov.tr/dumf

Araştırma Makalesi / Research Article

\title{
Bitlis İlinin Rüzgâr Enerjisi Potansiyelinin İstatistiksel Analizi
}

\author{
Statistical Analysis of The Wind Energy Potential of Bitlis Province
}

Faruk ORAL *

Bitlis Eren Üniversitesi, Makine Mühendisliği Bölümü, Bitlis

foral@ beu.edu.tr ORCID: 0000-0002-4114-0785

\begin{tabular}{l} 
MAKALE BİLGILERİ \\
\hline Makale geçmişi: \\
Geliş: 6 Aralık 2019 \\
Düzeltme: 18 Mart 2020 \\
Kabul: 1 Nisan 2020 \\
\hline Anahtar kelimeler: \\
Rüzgâr enerjisi, rüzgâr güç yoğunluğu, \\
Weibull dağılımı, Bitlis
\end{tabular}

\begin{abstract}
ÖZET
Bu çalışmada, Bitlis ilinin rüzgâr enerji potansiyeli, Bitlis meteoroloji istasyonunda onar dakikalık olarak ölçülen rüzgâr verileri kullanılarak araştırılmıştır. Rüzgâr verilerinin istatistiksel analizinde, Weibull dağılımı kullanılmıştır. Analiz sonucunda, rüzgâr hızı ve güç yoğunluğunun ortalama değeri hem gözlemlenen hem de Weibull dağılımına göre belirlenmiştir. Weibull dağılımına göre yıllık ortalama rüzgâr hızı ve güç yoğunluğu değerleri sırasıyla $3.26 \mathrm{~m} / \mathrm{s}$ ve $49.77 \mathrm{~W} / \mathrm{m}^{2}$ olarak bulunmuştur. Rüzgar hızının yönlere göre değişimi belirlenmiş ve hakım rüzgar yönünün \%27.5 frekans değerinde Güney-Güneybatı istikametinde olduğu tespit edilmiştir. Rüzgâr verilerinin gözlemlenen ile Weibull dağılımı sonuçlarının birbirine yakın olduğu bulunmuştur. Ayrıca rüzgâr hızı ve güç yoğunluğunun yüksekliğe göre değişimi belirlenmiştir.
\end{abstract}

Doi: $10.24012 /$ dumf. 655780

\begin{tabular}{|c|c|}
\hline ARTICLE INFO & ABSTRACT \\
\hline Article history: & \multirow{6}{*}{$\begin{array}{l}\text { In this study, the wind energy potential of the Bitlis province is investigated using the wind data measured in every } \\
\text { ten minutes on the Bitlis meteorological station. In statistical analysis of wind data, Weibull distribution is used. } \\
\text { As a result of the analysis, the average value of wind speed and power density were determined according to both } \\
\text { observed and Weibull distributions. According to the Weibull distribution, annual average wind speed and power } \\
\text { density values were found as being } 3.26 \mathrm{~m} / \mathrm{s} \text { and } 49.77 \mathrm{~W} / \mathrm{m}^{2} \text {, respectively. The variation of the wind speed } \\
\text { according to the directions was obtained and it was defined that the dominant wind direction was in the South- } \\
\text { Southwest direction with a frequency of } 27.5 \% \text {. It was found that observed wind data and Weibull distribution } \\
\text { results were close to each other. In addition, the change of wind speed and power density according to height was } \\
\text { also determined. }\end{array}$} \\
\hline Received: 6 December 2019 & \\
\hline Revised: 18 March 2020 & \\
\hline Accepted: 1 April 2020 & \\
\hline Keywords: & \\
\hline $\begin{array}{l}\text { Wind energy, wind power density, } \\
\text { Weibull distribution, Bitlis }\end{array}$ & \\
\hline
\end{tabular}

* Yazışmaların yapılacağı yazar 


\section{Giriș}

Tüm dünyada enerji üretim ve tüketiminde atıklar sonucu oluşan çevresel olumsuzluklar, artan enerji talebi, yenilenebilir enerji kaynaklarını, enerji üretimi bakımından önemli hale getirmiştir. Yenilenebilir temiz enerji kaynaklarından biri olan rüzgâr enerjisi, kinetik haldeki hava akımıdır. Rüzgâr, güneşin dünya yüzeyini ve atmosferi eşit düzeyde 1sıtmaması sonucu oluşan sıcaklık farklılıkları neticesinde meydana gelir. Rüzgârın sahip olduğu bu kinetik enerji, rüzgâr türbinleri yardımı ile mekanik enerjiye ve sonrasında elektrik enerjisine dönüştürülebilir.

Enerji üretimi amaçlı rüzgâr potansiyelinin belirlenmesinde, rüzgâr hızı ve yönü verileri kullanılır. Rüzgâr verilerinin analizinde Weibull ve Rayleigh dağılımları en fazla kullanılan yöntemlerdir. Weibull dağılımı iki parametreye, Rayleigh dağılımı ise tek parametreye sahiptir. Weibull dağılımı iki parametreli olduğu için Rayleigh dağılımına göre daha esnektir.

Türkiye'de çeşitli yerlerin rüzgâr enerjisi potansiyeli araştırılmıştır. Karslı ve Geçit [1], yaptıkları çalışmada, Gaziantep-Nurdağı bölgesinin rüzgâr gücü potansiyelini incelemişlerdir. Weibull dağılımına göre yapılan analizde, bölgenin ortalama rüzgâr hızı ve güç yoğunluğu değerlerini belirlemişlerdir. Özerdem ve Türkeli [2], çalışmalarında, seçilen bir üniversite yerleşke alanında rüzgâr karakteristiğini incelemişlerdir. Analizde; aylık ve yıllık ortalama rüzgar hızını, rüzgar yönü, rüzgar türbülans değerini, Weibull parametrelerini hesaplamışlardır. Köse vd. [3], Kütahya bölgesi rüzgâr enerji potansiyeli ve rüzgâr verilerinin analizini incelemişlerdir. $\mathrm{Bu}$ amaçla bölgede 20 aylık rüzgâr verilerini kullanarak 30 m yükseklik için ortalama rüzgâr hızı ve değerini bulmuşlardır. Akpınar ve Akpınar [4], Elazığ, Maden bölgesinin yıllık ortalama rüzgâr hızını $5.63 \mathrm{~m} / \mathrm{s}$, yıllık ortalama güç yoğunluğunu $244.65 \mathrm{~W} / \mathrm{m}^{2}$ olarak bulmuşlardır. Bilgili vd. [5], yaptıkları çalışmada, Antakya ve İskenderun bölgesinin rüzgâr enerji potansiyelini incelemişlerdir. $\mathrm{Bu}$ amaç ile 1997 ile 2001 yılları arasında ölçülen rüzgâr verilerini kullanmışlardır. Şahin vd. [6], Doğu Akdeniz bölgesi için; 1992-2001 yılları arasında rüzgâr verileri kullanarak, $25 \mathrm{~m}$ yükseklik için ortalama rüzgâr güç yoğunluğu değerini $500 \mathrm{~W} / \mathrm{m}^{2}$ olarak hesaplamışlardır. Gökçek vd. [7], Kırklareli bölgesi rüzgâr karakteristiği ve potansiyelini incelemişlerdir. 2004 y1lı ölçülen rüzgâr verilerini kullanarak, ortalama rüzgâr hızını ve güç yoğunluğu değerini belirlemişlerdir. Korukçu [8], çalışmasında Belen ve Gökçeada bölgelerinde $50 \mathrm{~m}$ yüksekliğinde yıllık ortalama rüzgâr hızları 10.2 $\mathrm{m} / \mathrm{s}$, güç yoğunluğu değerleri ise sirasıyla 1581 $\mathrm{W} / \mathrm{m}^{2}$ ve $1297 \mathrm{~W} / \mathrm{m}^{2}$ olarak bulmuştur. Oral vd. [9], Sakarya - Esentepe bölgesi rüzgâr enerji potansiyelini araştırmışlardır. $30 \mathrm{~m}$ yükseklikte ölçülen rüzgâr verilerini kullanarak, yıllık ortalama rüzgâr hızı ve güç yoğunluğu değerini bulmuşlardır. Bilgili vd. [10], Türkiye'nin güneyinde bulunan dokuz yerleşim yerinin rüzgâr enerji potansiyelini incelemişlerdir. Analiz sonucunda incelenen bölgelerin rüzgâr enerji potansiyellerinin yüksek olduğunu, rüzgâr türbini kurulmasına elverişli bölgelerim olduğunu belirtmişlerdir.

$\mathrm{Bu}$ çalışmanın amacı; bugüne kadar rüzgâr enerjisi bakımından henüz daha araştırılmayan Bitlis ilinin rüzgâr enerji potansiyelini belirlemektir. Rüzgâr potansiyelinin belirlenmesinde, Bitlis meteoroloji istasyonunda ölçülen rüzgâr verileri kullanılmıştır. Rüzgâr verilerinin analizinde Weibull dağılımı kullanılmıştır. Weibull dağılımı kullanılarak yapılan analiz sonuçları, gözlemlenen verilerin sonuçları ile karşılaştırılmıştır. Analiz sonucunda, ortalama rüzgâr hızı, rüzgâr hızının saatlik ve aylık değişimi, rüzgârın hâkim esme yönü, ortalama rüzgâr gücü yoğunluğu, yüksekliğe göre ortalama rüzgâr hızı ve güç yoğunluğunun değişimi belirlenmiştir. Çalışmada, Matlab ve WindPRO programları kullanılmıştır.

\section{Materyal ve Matematiksel Metot}

Bir bölgenin rüzgâr enerjisi potansiyelinin belirlenmesinde rüzgâr verileri kullanılır. $\mathrm{Bu}$ çalışmada Meteoroloji Genel Müdürlüğü'nün Bitlis meteoroloji istasyonundan elde edilen rüzgâr verileri kullanılmıştır. Söz konusu istasyonun rüzgâr potansiyelinin araştırılacağ1 alanın uygun yerinde bulunması, rüzgâr verilerinin buradan alınmasında etkili olmuştur. 
Ölçüm istasyonu, 252529 E, 4262353 N (UTM koordinat sistemine göre) koordinatlarında olup deniz seviyesinden $1794 \mathrm{~m}$ yüksekliğindedir. Çalışmada, Bitlis meteoroloji istasyonunda 10 metre yükseklikte ölçülen 2011 ve 2012 yıllarını kapsayan rüzgâr verileri kullanılmıştır. Rüzgâr verileri, onar dakikalık ortalamalar halinde hız ve yön değerlerinden oluşmaktadır. Belirli bir zaman aralığında ölçülen rüzgâr değerlerinde farklı tarih ve zamanlarda eşit rüzgâr hızları gözlemlenebilmektedir. Bir rüzgâr serisinde, bir rüzgâr hızının $\left(v_{i}\right)$ gözlemlenen toplam sayısı $m_{i}$ ise, bu rüzgâr hızının esme ihtimali $p\left(v_{i}\right)$;

$$
p\left(v_{i}\right)=\frac{m_{i}}{n}
$$

eşitliği ile ifade edilir. Burada $n$, rüzgâr serisindeki ölçüm değerleri sayısını veya toplam gözlem sayısını ifade etmektedir. Rüzgâr verilerinin değerlendirilmesinde en önemli özelliklerden birisi ortalama rüzgâr hızıdır. Ortalama rüzgâr hızı; ölçülen veya gözlemlenen rüzgâr hızı değerlerinin ortalamasıdır. Bir rüzgâr veri setinin değişkenliği de önemlidir. Bir seriyi meydana getiren rüzgâr hızı değerlerinin ortalama rüzgâr hızı değerinden farklarının kareleri ortalamasının karekökü değeri, standart fark olarak ifade edilir. Bir rüzgâr serisinin ortalama hızı $\left(v_{m}\right)$ ve standart farkı $(\sigma)$ aşağıda verilen eşitlikler ile hesaplanır.

$$
\begin{aligned}
& v_{m}=\frac{1}{n} \sum_{i=1}^{n} v_{i}=\frac{1}{n} \sum_{i=1}^{w} m_{i} v_{i} \\
& \sigma=\left[\frac{1}{n-1} \sum_{i=1}^{n}\left(v_{i}-v_{m}\right)^{2}\right]^{1 / 2}
\end{aligned}
$$

Burada $w$, gözlemlenen farklı rüzgâr hızı sayısını ifade etmektedir. $v$ hızında, $A$ dikey kesit alanından akan bir rüzgarın sahip olduğu güç $\left(P_{v}\right)$ ile belirli tarih aralığında gözlemlenen rüzgâr serisinin ortalama güç yoğunluğu $\left(P_{\mathrm{m}}\right)$, aşağıda verilen eşitlikler ile ifade edilir.

$$
\begin{aligned}
& P_{v}=\frac{1}{2} \rho A v^{3} \\
& P_{m}=\frac{1}{2} \rho A \sum_{i=1}^{w} p\left(v_{i}\right) v_{i}{ }^{3}
\end{aligned}
$$

Weibull dağılımı birçok çalışmada [2-11], rüzgâr verilerinin analizinde ve rüzgâr enerjisi potansiyelinin belirlenmesinde kullanılmıştır. Rüzgâr enerjisi ile ilgili yapılan birçok çalışmada, rüzgâr hızı verilerinin iki parametreli Weibull dağılımı özelliği gösterdiği belirlenmiştir [3-14]. Weibull olasılık yoğunluk fonksiyonu, şekil (k) ve ölçek (c) parametrelerinden oluşur. $\mathrm{Bu}$ fonksiyon, herhangi bir rüzgâr hızında, esme sayısını ifade eder. Bu dağılımın olasılık yoğunluk fonksiyonu aşağıda verilen eşitlik ile ifade edilir [16].

$$
f(v)=\frac{k}{c}\left(\frac{v}{c}\right)^{k-1} \exp \left[-\left(\frac{v}{c}\right)^{k}\right]
$$

Weibull olasılık yoğunluk fonksiyonu rüzgâr verilerinin tamamını temsil etmektedir. Belirli bir rüzgâr hızı değerinden küçük yada eşit gerçekleşme olasılığını vermekte olan Weibull kümülatif dağılım fonksiyonu aşağıdaki eşitlik ile ifade edilebilir [15].

$$
F(v)=1-\exp \left[-\left(\frac{v}{c}\right)^{k}\right]
$$

Literatürde Weibull yoğunluk fonksiyonu parametrelerinin belirlenmesinde, çeşitli metotlar geliştirilmiştir (Grafik yöntemi, En yüksek olabilirlik yöntemi, Moment yöntemi, Güç yoğunluğu yöntemi, Ortalama rüzgâr hız1standart sapma yöntemi ve benzeri gibi). Grafik, moment ve en yüksek olabilirlik metotları bu yöntemlerin başında gelmektedir. Bu çalışmada Weibull yoğunluk fonksiyonunun parametrelerinin belirlenmesinde, en yüksek olabilirlik metodu (EYO) kullanılmıştır. Bu metotta; gözlemlenen her bir rüzgâr hızı değerleri, birbirlerinden bağımsız olduklarından, yapılan $\mathrm{n}$ adet gözlemde bu olayların meydana gelme olasılığ1;

$$
L L\left(v_{1}, v_{2} \ldots . v_{n}, k, c\right)=\prod_{i=1}^{n} f\left(v_{i} ; k, c\right)
$$

biçiminde olabilirlik fonksiyonu ile ifade edilebilir [15-17]. Bu fonksiyonu en yüksek yapan $(k)$ ve $(c)$ değerleri, en yüksek olabilirlik tahminleridir. $\mathrm{Bu}$ yöntemde, çözümü kolaylaştırmak için Eşitlik (8)'in her iki tarafının logaritması alınmak suretiyle olabilirlik fonksiyonu toplam haline getirilir. Eşitlik (6), 
Eşitlik (8)'de yerine konulup elde edilen yeni eşitliğin logaritması alınması durumunda;

$$
\ln L L=n(\ln k-k \ln c)+(k-1) \sum_{i=1}^{n} \ln \left(v_{i}\right)-\frac{1}{c^{k}} \sum_{i=1}^{n}\left(v_{i}\right)^{k}
$$

eşitliği elde edilir. Bulunan son eşitliğgi, $(c)$ ve $(k)$ parametrelerine göre ayrı ayrı birinci dereceden kısmi türevi alınıp sıfıra eşitlenirse, aşağıdaki eşitlikler bulunur.

$$
\begin{aligned}
& c=\left(\frac{1}{n} \sum_{i=1}^{n} v_{i}^{k}\right)^{1 / k} \\
& k=\left(\frac{\sum_{i=1}^{n} v_{i}^{k} \ln v_{i}}{\sum_{i=1}^{n} v_{i}^{k}}-\frac{\sum_{i=1}^{n} \ln v_{i}}{n}\right)^{-1}
\end{aligned}
$$

$\mathrm{Bu}$ son eşitliklerinin iteratif olarak çözülmesi ile $(k)$ ve $(c)$ parametrelerin EYO tahminleri elde edilir. Weibull dağılımına göre, ölçülen rüzgâr h1zı verilerinin ortalama ve standart sapma değerleri aşağıdaki eşitlikler ile ifade edilir [12].

$$
\begin{aligned}
& v_{m}=\mathrm{c} \Gamma\left(1+\frac{1}{k}\right) \\
& \sigma=\mathrm{c}\left[\Gamma\left(1+\frac{1}{k}\right)-\Gamma^{2}\left(1+\frac{1}{k}\right)\right]^{1 / 2}
\end{aligned}
$$

Burada, $Г($.$) gama fonksiyonu olarak ifade$ edilmektedir.

Weibull dağılımı için $v$ esme hızına sahip rüzgârın meydana getirebileceği ortalama rüzgâr gücü yoğunluğu aşağıdaki eşitlikle hesaplanır [12].

$P_{m}=\int_{0}^{\infty} \frac{1}{2} \rho v^{3} f(v) d v=\frac{1}{2} \rho c^{3} \Gamma\left(1+\frac{3}{k}\right)$

Rüzgâr hızı üzerinde, arazinin topoğrafik yapısının engelleyici etkisi olacaktır. Rüzgâr hızı, yükseklik arttıkça arazi pürüzlülüğüne bağlı olarak logaritmik şekilde artmaktadır. Rüzgâr türbinlerinden üretilebilecek enerji miktarının hesaplanmasında, türbin hub yüksekliğinde rüzgâr hızı değerlerinin bilinmesi gerekmektedir. Belirli bir yükseklikte ölçülmüş rüzgâr hızları kullanılarak istenilen herhangi bir yükseklikteki rüzgâr hızları, aşağıda verilen kuvvet kanunu eşitliği ile hesaplanabilir [18].

$$
\frac{v}{v_{z}}=\left(\frac{h}{h_{z}}\right)^{\alpha}
$$

Burada $v ; h$ ölçüm yüksekliğinde gözlemlenen rüzgâr hızını, $v_{z} ; h_{z}$ yüksekliğinde hesaplanacak rüzgâr hızı değerini ifade etmektedir. Eşitlikte kullanılan üstel terim $\alpha$; rüzgâr ölçümünün yapıldığı yerdeki yüzey pürüzlülüğüne ve atmosferik kararlılık gibi özelliklere bağlı olarak 0.05-0.5 arasında değişir. Bu çalışmada $\alpha$ üssü değeri 0.15 olarak alınmıştır.

\section{Analiz Sonuçları}

2011 ve 2012 yıllarını kapsayan iki yıllık rüzgâr verileri kullanılarak Eşitlik (2), Eşitlik (3) ve Eşitlik (5) yardımı ile gözlemlenen (gerçek) verilerin ortalama rüzgâr hızı $\left(\mathrm{v}_{\mathrm{m}}\right)$, standart sapma ve ortalama güç yoğunluğu değerleri bulunmuştur. Rüzgâr verilerinin analizinde, Weibull dağılımı kullanılmıştır. Weibull dağılımı parametrelerinin belirlenmesinde EYO metodu, bu metodundan elde edilen eşitliklerin sayısal çözümünde Newton-Raphson yöntemi kullanılmıştır.

İki yıllık rüzgâr verilerinin gözlemlenen ve Weibull dağılımı sonuçları Tablo 1'de verilmiştir. Tablo 1, incelendiğinde, rüzgâr hız1 ve güç yoğunluğunun gözlemlenen ortalama değerleri sirasıyla $3.13 \mathrm{~m} / \mathrm{s}, \quad 50.01 \mathrm{~W} / \mathrm{m}^{2}$ bulunmuştur. Gözlemlenen rüzgar h1z1 değerlerinin standart sapması 2.2449 olarak hesaplanmıştır. Weibul dağılımının $k$ ve $c$ parametreleri sirasiyla 1.49 ve $3.61 \mathrm{~m} / \mathrm{s}$ olarak bulunmuştur. Rüzgâr verilerinin Weibull dağılımına göre, rüzgar hız ve güç yoğunluğunun ortalama değeri sırası ile, $3.26 \mathrm{~m} / \mathrm{s}$ ve 49.77 $\mathrm{W} / \mathrm{m}^{2}$ olarak bulunmuştur. $\mathrm{Bu}$ dağılıma göre rüzgar hızlarının standart sapma değeri 2.17899 olarak hesaplanmıştır. Tablo 1'de görüldüğü gibi, yapılan analiz neticesinde Weibull dağılımı sonuçlarının gözlemlenen değerlere yakın olduğu belirlenmiştir. 
Tablo 1. Yıllık ortalama rüzgâr hızı, standart sapma ve güç yoğunluğu değerleri

Table 1. Annual average wind speed, standard deviation and average power density values

\begin{tabular}{llllll}
\hline & $\begin{array}{l}\mathrm{V}_{\mathrm{m}} \\
(\mathrm{m} / \mathrm{s})\end{array}$ & $\mathrm{k}$ & $\begin{array}{l}c \\
(\mathrm{~m} / \mathrm{s})\end{array}$ & $\sigma$ & $\begin{array}{l}P_{m} \\
\left(\mathrm{~W} / \mathrm{m}^{2}\right)\end{array}$ \\
\hline $\begin{array}{l}\text { Gözlemlenen } \\
\text { değer }\end{array}$ & 3.13 & - & - & 2.2449 & 50.01 \\
$\begin{array}{l}\text { Weibull } \\
\text { dağ1lımı }\end{array}$ & 3.26 & 1.490 & 3.61 & 2.1789 & 49.77 \\
\hline
\end{tabular}

İki yıllık rüzgâr verilerinin Weibull dağılımına göre sonuçları Tablo 2'de verilmiştir. Şekil 1'de rüzgâr hızının frekans dağılımı, Şekil 2 ve Şekil 3 'de rüzgâr hızı ve frekansının sektörel değişimi verilmiştir.

Tablo 2. Weibull dă̆ılımına göre sektörel frekans değerleri

Table 2. According to the Weibull distribution, sectoral average wind speed, Weibull

parameters and frequency distribution

\begin{tabular}{lllll}
\hline Sectör & $\begin{array}{l}\mathrm{v}_{\mathrm{m}} \\
(\mathrm{m} / \mathrm{s})\end{array}$ & $\begin{array}{l}c \\
(\mathrm{~m} / \mathrm{s})\end{array}$ & $\begin{array}{l}\mathrm{k} \\
(\%)\end{array}$ \\
\hline 0-N & 2.24 & 2.53 & 1.844 & 9.3 \\
1-NNE & 2.11 & 2.36 & 1.677 & 13.9 \\
2-NEE & 2.55 & 2.87 & 1.861 & 14.0 \\
3-E & 3.22 & 3.60 & 1.673 & 3.2 \\
4-ESE & 2.42 & 2.41 & 0.991 & 0.7 \\
5-SSE & 2.78 & 2.91 & 1.140 & 0.8 \\
6-S & 4.16 & 4.68 & 1.847 & 4.9 \\
7-SSW & 5.00 & 5.63 & 1.970 & 27.5 \\
8-WSW & 2.87 & 3.22 & 1.695 & 4.4 \\
9-W & 2.98 & 3.33 & 1.635 & 2.9 \\
10-WNW & 2.80 & 3.16 & 2.116 & 7.4 \\
11-NNW & 2.34 & 2.65 & 2.071 & 11.0 \\
Ortalama & 3.26 & 3.61 & 1.490 & 100 \\
\hline
\end{tabular}

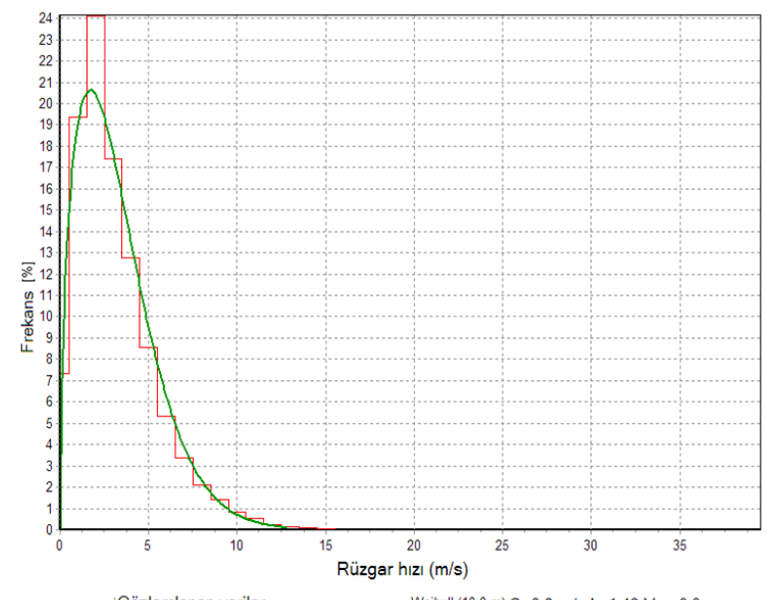

Şekil 1. Rüzgâr hızı frekans dă̆ılımı

Figure 1. Frequency distribution of wind speed

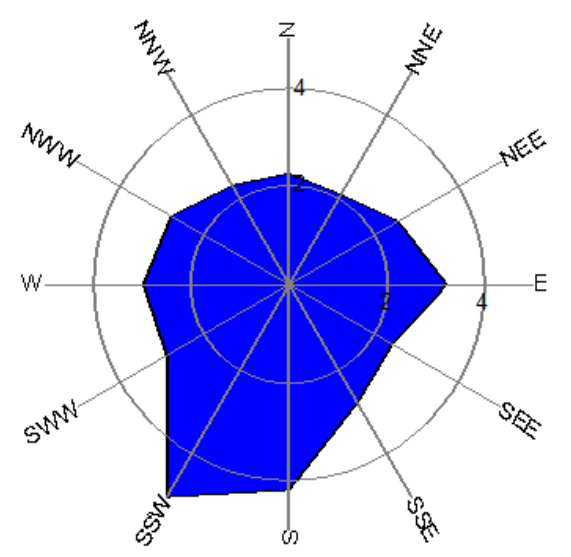

Şekil 2. Rüzgâr hızının sektörel değişimi $(\mathrm{m} / \mathrm{s})$

Figure 2. Sectoral changing of wind speed

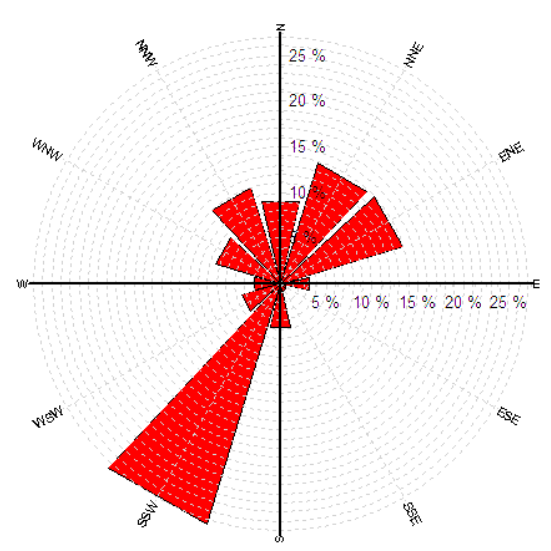

Şekil 3. Rüzgâr yönünün sektörel frekans değişimi (\%)

Figure 3. Sectoral frequency changing of Wind direction 


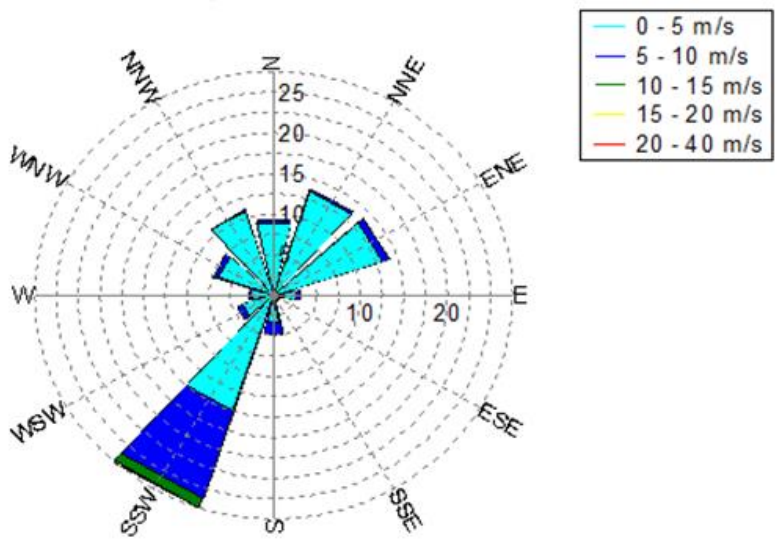

Şekil 4. Rüzgâr hızı değerlerinin sektörel frekans değişim (\%)

Figure 4. Sectoral frequency changing of wind speed

Tablo 2, Şekil 1, Şekil 2 ve Şekil 3'de verilen bilgilerden, ortalama rüzgâr hızı $\left(v_{m}\right) 3.26 \mathrm{~m} / \mathrm{s}$, Weibull $(k)$ şekil parametresi 1.49, $(c)$ ölçek parametresi $3.61 \mathrm{~m} / \mathrm{s}$ bulunmuştur. Rüzgâr hızının en büyük frekans1 \%27.5 değerinde Güney-Güneybatı yönünde gerçekleştiği, bu yönde ortalama rüzgâr hız1 $5.0 \mathrm{~m} / \mathrm{s}$, Weibull şekil parametresi 1.97 ve ölçek parametresi $5.63 \mathrm{~m} / \mathrm{s}$ olarak bulunmuştur. Ortalama en büyük rüzgâr hızı Güney-Güneybatı istikametinde ve $5 \mathrm{~m} / \mathrm{s}$ değerinde gerçekleşmiştir. Weibull şekil parametresinin en büyük değerinin 2.116 değerinde Bat1-Kuzeybatı, ölçek parametresinin en büyük değerinin ise $5.63 \mathrm{~m} / \mathrm{s}$ olarak GüneyGüneybatı istikametinde olduğu görülmüştür. Bölgede hâkim rüzgâr yönünün \%27.5 frekans ile Güney-Güneybatı yönünde gerçekleştiği bulunmuştur. Kuzey-Kuzeydoğu ve DoğuKuzeydoğu istikametlerinde rüzgâr frekansı değerlerinin büyük olduğu görülmüştür. Şekil 4'de rüzgâr hızı değerlerinin sektörel frekans değişimi verilmiştir. $5-10 \mathrm{~m} / \mathrm{s}$ arasındaki rüzgâr hızlarının en büyük frekans değerinin hâkim rüzgâr yönü olan Güney-Güneybatı istikametinde olduğu belirlenmiştir.

Şekil 5'de, Weibull dağılımına göre, rüzgâr hızı ve yönünün saatlik ortalama değişimi verilmiştir. Şekil 5'de görüldüğü gibi, ortalama rüzgâr hız değerlerin, saat 03:00 ile 10:00 arasında artma eğiliminde olduğu, sonraki saatlerde azalarak saat 15:00'da normalleştiği görülmüştür.

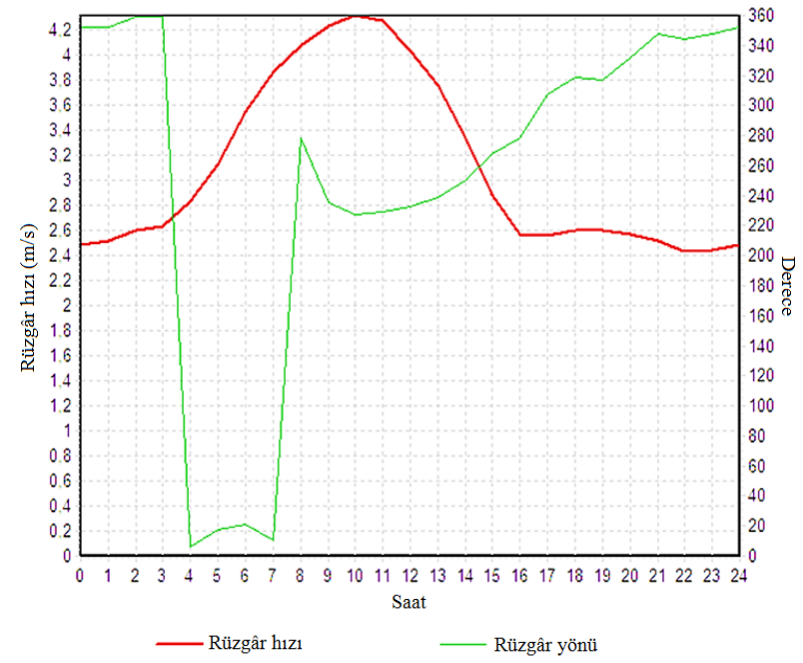

Şekil 5. Rüzgâr hızı ve yönünün saatlik değişimi

Figure 5. Hourly changing of average wind speed and directions

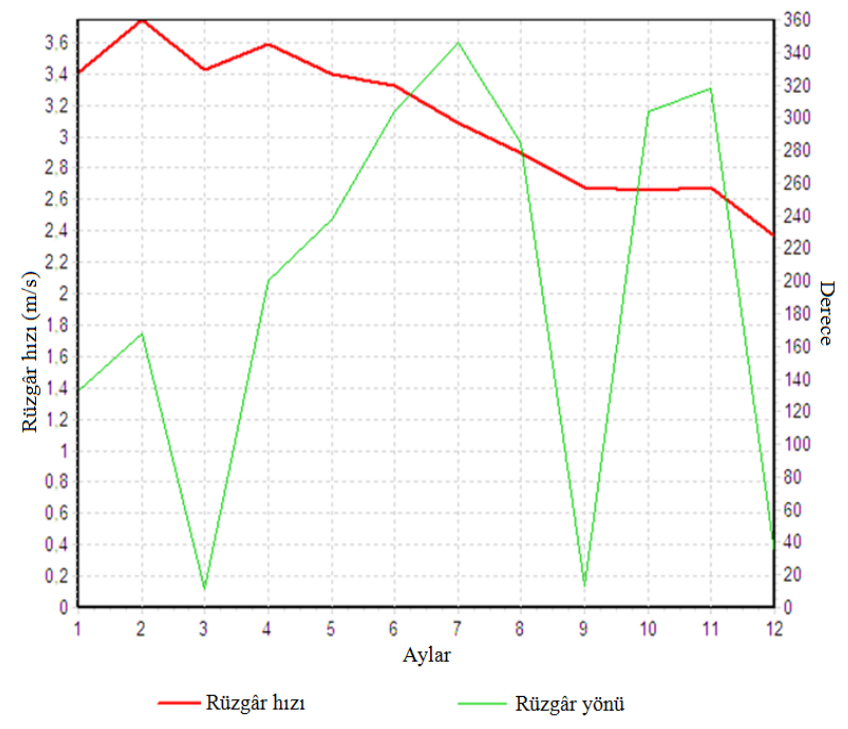

Şekil 6. Aylık ortalama rüzgâr hızı ve yönünün değişimi.

\section{Figure 6. Changing of monthly average wind speed and directions}

Şekil 6'da, Weibull dağılımına göre rüzgâr hızı ve yönünün aylık ortalama değerleri verilmiştir. Rüzgâr hızının en büyük ortalama değeri $3.8 \mathrm{~m} / \mathrm{s}$ ile Şubat ayında gerçekleşmiştir. En düşük ortalama rüzgar hızı değeri $2.4 \mathrm{~m} / \mathrm{s}$ ile Aralık ayında olmuştur. Rüzgâr hızının ilk altı ayının ortalama değerleri diğer aylara göre daha yüksek olduğu görülmüştür.

Referans ölçüm yüksekliği olan 10 metredeki rüzgâr hızı verileri kullanılarak, farklı yükseklikteki ortalama rüzgâr hızı, güç 
yoğunluğu ve Weibull parametre değerleri, Eşitlik (14) ve Eşitlik (15) yardımı ile hesaplanarak Tablo 3'de verilmiştir. Tablo incelendiğinde; yüksekliğin artması ile birlikte yıllık ortalama rüzgâr hızı, Weibul parametreleri, yıllık ortalama güç ve enerji yoğunluğu değerlerini arttığ belirlenmiştir. 200 m yükseklik için Weibull dağılımına göre, rüzgâr hızı ortalamas $15.16 \mathrm{~m} / \mathrm{s}$, c ve $\mathrm{k}$ parametrelerinin değerleri sirasiyla, $5.8(\mathrm{~m} / \mathrm{s}), 2.12$ olarak bulunmuştur. Yine bu yükseklik için ortalama güç ve enerji yoğunlukları sırasıyla, 127.97 $\mathrm{W} / \mathrm{m}^{2}$ ve $1121 \mathrm{kWh} / \mathrm{m}^{2}$ olarak hesaplanmıştır.

Tablo 3. Yüksekliğe göre ortalama rüzgâr hızl, Weibull parametreleri ve güç yoğunluğu değişimi.

Table 3. According to height, average wind speed, Weibull parameters and power density change

\begin{tabular}{|c|c|c|c|c|c|}
\hline $\begin{array}{l}\text { Height } \\
(\mathrm{m})\end{array}$ & $\begin{array}{l}v_{\mathrm{m}} \\
(\mathrm{m} / \mathrm{s})\end{array}$ & $\begin{array}{l}\mathrm{c} \\
(\mathrm{m} / \mathrm{s})\end{array}$ & $\mathrm{k}$ & $\begin{array}{l}\mathrm{P}_{\mathrm{m}} \\
\left(\mathrm{W} / \mathrm{m}^{2}\right)\end{array}$ & $\begin{array}{l}\text { Rüzgâr } \\
\text { enerjisi } \\
\left(\mathrm{kWh} / \mathrm{m}^{2}\right)\end{array}$ \\
\hline 10 & 3.26 & 3.6 & 1.49 & 49.77 & 436 \\
\hline 20 & 3.61 & 4.0 & 1.53 & 64.84 & 568 \\
\hline 30 & 3.83 & 4.3 & 1.58 & 74.54 & 653 \\
\hline 40 & 4.00 & 4.5 & 1.62 & 81.74 & 716 \\
\hline 50 & 4.13 & 4.6 & 1.66 & 87.44 & 766 \\
\hline 60 & 4.25 & 4.8 & 1.70 & 92.24 & 808 \\
\hline 70 & 4.35 & 4.9 & 1.73 & 96.23 & 843 \\
\hline 80 & 4.44 & 5.0 & 1.77 & 99.77 & 874 \\
\hline 90 & 4.52 & 5.1 & 1.80 & 102.97 & 902 \\
\hline 100 & 4.60 & 5.2 & 1.84 & 105.82 & 927 \\
\hline 110 & 4.67 & 5.3 & 1.87 & 108.56 & 951 \\
\hline 120 & 4.74 & 5.3 & 1.90 & 111.07 & 973 \\
\hline 130 & 4.80 & 5.4 & 1.93 & 113.47 & 994 \\
\hline 140 & 4.86 & 5.5 & 1.96 & 115.75 & 1014 \\
\hline 150 & 4.91 & 5.5 & 1.99 & 117.92 & 1033 \\
\hline 160 & 4.97 & 5.6 & 2.02 & 120.09 & 1052 \\
\hline 170 & 5.02 & 5.7 & 2.04 & 122.15 & 1070 \\
\hline 180 & 5.07 & 5.7 & 2.07 & 124.09 & 1087 \\
\hline 190 & 5.12 & 5.8 & 2.09 & 126.03 & 1104 \\
\hline 200 & 5.16 & 5.8 & 2.12 & 127.97 & 1121 \\
\hline
\end{tabular}

Şekil 7'da sektörel olarak yıllık ortalama enerji yoğunluğu verilmiştir. $\mathrm{Bu}$ şekilden de görülebileceği gibi ortalama enerji yoğunluğunun en büyük değeri, güney-güneybatı yönünden esen rüzgâr hızlarından olmuştur. Enerji üretimi bakımından hâkim yön, güneygüneybatı istikametindedir. $\mathrm{Bu}$ yönde esen rüzgâr hızı ortalamasının ağırlıklı değerleri, 5-10 $\mathrm{m} / \mathrm{s}$ ve $10-15 \mathrm{~m} / \mathrm{s}$ aralığında gerçekleşmiştir.

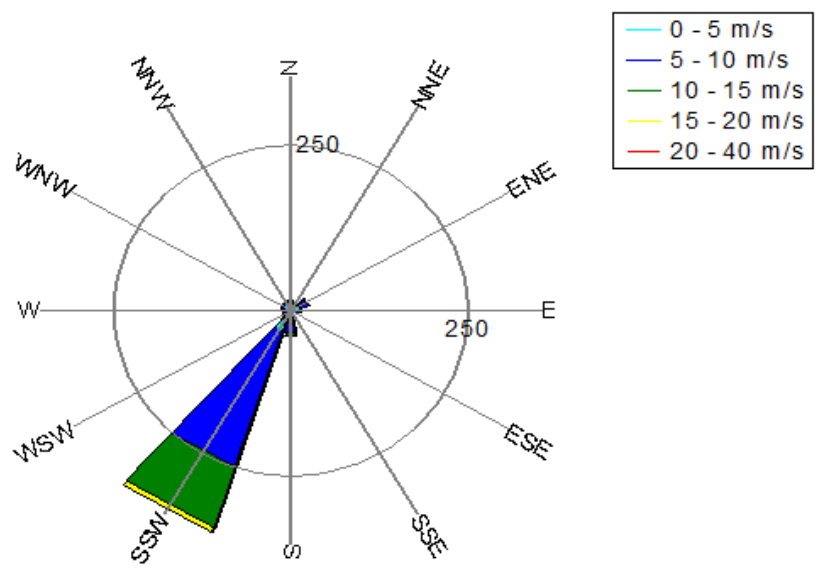

Şekil 7. Sektörel ortalama enerji yoğunluğu $\left(\mathrm{kWh} / \mathrm{m}^{2}\right)$

\section{Figure 7. Sectoral average energy density}

\section{Sonuçlar}

$\mathrm{Bu}$ çalışmada; Bitlis ilinin rüzgâr enerjisi potansiyeli incelenmiştir. Araştırmada Bitlis meteoroloji istasyonundan alınan rüzgâr verileri kullanılmıştır. Rüzgâr verilerinin istatistiksel analizinde Weibull dağılımı kullanılmıştır. Weibull dağılımı sonuçları gözlemlenen değerlere göre karşılaştırılmıştır.

Rüzgâr verilerinin gözlemlenen değerlerinin analizi sonucunda; rüzgâr hızı ve güç yoğunluğunun ortalama değerleri sirasıyla, 3.13 $\mathrm{m} / \mathrm{s}$ ve $50.01 \mathrm{~W} / \mathrm{m}^{2}$ olarak bulunmuştur. Weibull dağılımına göre, rüzgâr hızı ve güç yoğunluğunun ortalama değerleri sirasılya, 3.26 $\mathrm{m} / \mathrm{s}$ ve $49.77 \mathrm{~W} / \mathrm{m}^{2}$ olarak belirlenmiştir. Rüzgâr verilerinin gözlemlenen ve Weibull sonuçlarının birbirine yakın değerlerde gerçekleştiği tespit edilmiştir.

Bölgede hâkim rüzgâr yönünün \%27.5 frekans değerinde Güney-Güneybatı istikametinin olduğu tespit edilmiştir. Hâkim yönde rüzgâr hızının ortalama değerinin $5 \mathrm{~m} / \mathrm{s}$ olduğu belirlenmiştir. Hâkim yönünde $5-10 \mathrm{~m} / \mathrm{s}$ 
arasındaki rüzgâr hızlarının önemsenecek frekans değerlerinde olduğu görülmüştür.

Weibull dağılımına göre ortalama rüzgâr hızı değerlerinin saatlik ve aylık değişimi incelenmiștir. Ortalama saatlik rüzgâr hızı değerlerinin saat 03:00 ile saat 10:00 arasında artış eğiliminde olduğu belirlenmiştir. Aylık ortalama rüzgâr hızının en büyük değeri Şubat ayında, en düşük değeri ise Aralık ayında gerçekleştiği bulunmuştur.

Bölgede rüzgâr hızı, Weibull parametreleri ve güç yoğunluğunun ortalama değerlerin yüksekliğe göre değişimi belirlenmiștir. Yüksekliğin artması ile birlikte ortalama rüzgâr hızının ve güç yoğunluğunun arttığı görülmüştür.

Artan enerji talebi ve yaşanan çevresel olumsuzluklar, rüzgâr enerjisi potansiyeli bakımından iyi olabilecek bölgelerin enerji üretimi bakımından değerlendirilmesini önemli kılmaktadır.

Sonuç olarak, bölgenin ölçüm yüksekliğinde ortalama rüzgâr hızı ve güç yoğunluğu değerlerinin düşük olması sebebiyle enerji üretimi bakımından elverişli olmadığını, yüksekliğe bağlı olarak ortalama rüzgâr hızı ve güç yoğunluğunun artması nedeniyle bölgenin yüksek rakımlı farklı kısımlarında yapılacak rüzgâr ölçümü ve analizi ile enerji üretimi bakımından uygun yerlerin olabileceği, hâkim rüzgâr yönünde $5-10 \mathrm{~m} / \mathrm{s}$ arasındaki rüzgâr hızı frekans değerlerinin büyük olması enerji üretimine olumlu katkılar verebileceği ve saatlik ortalama rüzgâr hızının $2.4 \mathrm{~m} / \mathrm{s}^{\prime}$ nin üzerinde olması durumunda da enerji üretimi amaçlı küçük güçlü rüzgâr türbinlerinin kullanımına elverişli olabileceği kanaati oluşmuştur.

\section{Kaynaklar}

[1] V.M. Karsli, C. Geçit, An investigation on wind power potential of Nurdağı-Gaziantep Turkey, Renewable Energy, 28(5), 823-830, 2003.

[2] B. Özerdem, M. Turkeli, An investigation of wind characteristics on the campus of Izmir Institute of Technology, Turkey, Renewable Energy, 28(7), 10131027, 2003.

[3] R. Kose, M.A. Ozgur, O. Erbas, A. Tugcu, The analysis of wind data and wind energy potential in Kutahya, Turkey, Renewable and Sustainable Energy Reviews, 8(3), 277-288, 2004.

[4] E.K. Akpınar, S. Akpınar, Determination of the wind energy potential for Maden-Elazig, Turkey, Energy
Conversion and Management, 45(18-19), 2901-2914, 2004.

[5] M. Bilgili, B. Şahin, A. Kahraman, Wind energy potential in Antakya and İskenderun regions, Turkey, Renewable Energy, 29(10), 1733-1745, 2004.

[6] B. Sahin, M. Bilgili, H. Akilli, The wind power potential of the eastern Mediterranean region of Turkey, Journal of Wind Engineering and Industrial Aerodynamics, 93(2), 171-183, 2005.

[7] M. Gökçek, A. Bayülken, Ș. Bekdemir, Investigation of wind characteristics and wind energy potential in Kirklareli, Turkey, Renewable Energy, 32(10), 17391752, 2007.

[8] M.Ö. Korukçu, Türkiye'de dört yerleşim yeri için rüzgâr enerjisi potansiyelinin belirlenmesi, Uludağ Üniversitesi Mühendislik-Mimarlık Fakültesi Dergisi, 16(1), 117-125, 2011.

[9] F. Oral, İ. Ekmekçi, N. Onat, Weibull distribution for determination of wind analysis and energy production, World Journal of Engineering, 12(3), 215-220, 2015.

[10] M. Bilgili, B. Şahin, E. Şimşek, Türkiye'nin güney, güneybatı ve batı bölgelerindeki rüzgâr enerjisi potansiyeli, Isı Bilimi ve Tekniği Dergisi, 30(1), 01-12, 2010.

[11] K. Ulgen, A. Hepbasli, Determination of Weibull parameters for wind energy analysis of Izmir, Turkey, International Journal of Energy Research, 26(6), 495506, 2002.

[12] A.N. Çelik, A statistical analysis of wind power density based on the Weibull and Rayleigh models at the southern region of Turkey, Renewable Energy, 29(4), 593-604, 2003.

[13] S. Persaud, D. Flynn, B. Fox, Potential for wind generation on the Guyana coastlands, Renewable Energy, 18(2), 175-189, 1999.

[14] I.Y.F. Lun, J.C. Lam, A study of Weibull parameters using long-term wind observations, Renewable Energy, 20(2), 145-153, 2000.

[15] J.V. Seguro, T.W. Lambert, Modern estimation of the parameters of the Weibull wind Speed distribution for wind energy analysis, Journal of Wind Engineering and Industrial Aerodynamics, 85(1), 75-84, 2000.

[16] M.N. Almalı, İki parametreli Weibull dağılışında parametrelerin tahminlenmesi için farklı yöntemlerin karşılaştırılması ve rüzgâr hızı verilerine uygulanması, Doktora Tezi, Yüzüncü Yıl Üniversitesi, Van, Türkiye, 2005.

[17] M.J.M. Stevens, P.T. Smulders, The estimation of the parameters of the Weibull wind speed distribution for wind energy utilization purposes, Wind Engineering, 3(2), 132-145, 1979.

[18] N. Eskin, H. Artar, S. Tolun, Wind energy potential of Gokceada Island in Turkey, Renewable and Sustainable Energy Reviews, 12(3), 839-851, 2008. 